\title{
Sustainable Development through Solicitude: Review of a Field Health Project in Cambodia with Implications for National Policy
}

\author{
Ellen A. Herda ${ }^{1 *}$ and Valerie G. Dzubur ${ }^{2}$ \\ ${ }^{1}$ University of San Francisco, California, United States. \\ *Correspondence: \\ Ellen A. Herda, PhD, University of San Francisco, California, \\ USA, Tel: + 510455 0656; E-mail: herdatemp@yahoo.com. \\ ${ }^{2}$ Samuel Merritt University, California, United States. \\ Received: 23 January 2018; Accepted: 08 February 2018
}

Citation: Ellen A Herda, Valerie G Dzubur. Sustainable Development through Solicitude: Review of a Field Health Project in Cambodia with Implications for National Policy. Nur Primary Care. 2018; 2(1): 1-6.

ABSTRACT
A significant key to sustainable development in any emerging country is a healthy population. Now is the time
for governments in such countries to not only build shiny new infrastructure, but also to assess and educate their
population on how to care for themselves and others. This report on development work in Cambodia, related
to type 2 diabetes, presents three aspects of our work: the concepts behind development activities guiding this
project; the relationship between solicitude and development; and a field project review. In order to set a context
for this development work, a short account of Cambodia's recent history is presented. This account is followed by
a discussion on development motifs and solicitude from the perspective of critical hermeneutics, and a report of
project activities with implications for Cambodian national policy.

Keywords

Cambodia, Critical Hermeneutics development, Diabetes, Solicitude, Sustainable development.

\section{Introduction}

Cambodia is currently emerging out from under the crushing blow of a devastating civil war [1] and after many years of both physical and psychological struggle [2], is now moving on with rapid economic progress. This progress can be seen in recently built infrastructure including roads, bridges, shopping malls and high rises; international investment and real estate companies setting up offices in Phnom Penh, the capitol; and increasing the capacity of a deep-water port in Sihanoukville. These observations have been noted during the numerous visits by the authors over the past several years. The outward view of a changing Cambodia is both remarkable and critical to the welfare of Cambodians. However, there is a sobering condition that affects many of the rural people living in villages through out most of Cambodia. This condition points to the serious health problems experienced on a daily basis by hundreds of thousands of people due to type 2 diabetes and related complications. One way to help address this situation is to carry out health assessments among the rural population and to work toward providing health education related to diabetes and good health in general, and for these activities to become part of the public space related to sustainable development. This article reviews both the theory and the activities that guide our development work in Cambodia. The authors are an anthropologist (Herda) and a family nurse practitioner (Dzubur). First, a Cambodian context is set below in terms of recent history and its consequences.

\section{Recent History of Cambodia and Consequences}

Between the years 1975 to 1979 , the Communist Khmer Rouge ruled Cambodia. Their objective was to make Cambodia a classless society. The hope of the leader, Pol Pot, was to turn Cambodia into an agrarian utopia. They forced people to work 20 hours a day. During this time period, it is estimated that 2 million people, one out of every four Cambodians, were killed through starvation, exhaustion, disease, horrific torture and execution. For those who lived through these years, food was so scarce that often people ate dirt or wood in order to try to stay alive. In the 1980's, Hollywood made a film, "The Killing Fields," that told this story of the Cambodian genocide to the wider world.

Today the outbreak of type 2 diabetes in Cambodia is thought, in part, to be a product of those years of starvation. During starvation, not enough nutrients come through the placenta and the fetus's pancreas - which produces insulin that prevents diabetes-will not develop correctly. Researchers from Brown University in 
the United States and Harbin Medical University in China found a rise in diabetes among people who were conceived during a famine or starvation on the part of the mother [3]. There may be multigenerational effects; changes in how genes function caused by famine may be passed on to future generations. This means Cambodians born long after the Khmer Rouge's regime may also suffer effects from those years of brutality. The field of epigenetics was born when researchers discovered the effects of starvation on future generations $[4,5]$. The origin of the study of epigenetics has evolved into a critical aspect of what today we call precision or personal medicine; we are learning how to diagnose and treat patients on a molecular level [6]. What this means, as Ethan Watters reports, is that our "DNA is not our destiny" and quoting from Moshe Szyf: "Epigenetics will have a dramatic impact on how we understand history, sociology, and political science" [7]. As tragic as it is to know that starvation (which could have been averted) can cause danger in the lives of future generations, it is highly significant that out of the original genetic research on populations that suffered from a lack of food, today we face a totally different, and amazingly bright, future in many fields, especially healthcare.

\section{The Changing Face of Development}

Traditionally, words that describe development regions are "Third World," "poor," "needy," "underdeveloped," "disadvantaged," and "developing economy," as well as others. Today, the World Health Organization (WHO) reports that approximately 1.2 billion [out of 7.6 billion] live in extreme poverty (less than one dollar per day) [8]. These people are in need of immediate relief and do not fall under the normal nomenclature of "development." This situation is too dire to think about development, or sustainable development. Theirs is a matter of relief and a stabilization of living conditions before development programs can have any effect on such populations. Another demarcation of development is provisional aid, which characterizes international development agencies, most notably the United National Development Program (UNDP) and the World Bank with International Monetary Fund (IMF) providing monitoring services. A determining assumption among these agencies is that successful development in poor countries is reflected in economic progress. While there is economic progress for some in these countries, the poor are still with us. Sustainable development is a concept that embraces all countries around the world working to meet the needs of this generation as well as future generations. Specifically, the Institute of International Sustainable Development (IISD) writes: "Sustainable development is development that meets the needs of the present without compromising the ability of future generations to meet their own needs" [9].

The 2030 Agenda for Sustainable Development and its Sustainable Development Goals (SDGs) of the United Nations has for its foundation the above meaning of sustainable development from the IISD. We agree in general with the definition and that the goals require "action on all fronts - governments, business, civil society and people everywhere all have a role to play" [9]. However, specifically, we hold that sustainable development needs a particular predicate, and in our thinking, it is solicitude - care for oneself and the other. Solicitude here would manifest most directly, and perhaps most obviously, in the area of healthcare. A country cannot succeed for all people, or even most of the people, without people's health being center in the name of sustainable development. A healthy population is central to economic success. While it is true if people have more income, they can afford better healthcare. However, three fronts need to be addressed here: uneven economic development (portraying a developing country with mostly poor and a few rich); a lack of awareness of how one gains and maintains health in view of emerging fast food industries, a modest increase in spendable income allowing people to consume more white rice; and the genetic factor. Development, for the most part, has focused on economic development leaving healthcare access and healthcare education seriously behind.

\section{Solicitude}

Healthcare draws attention of officials at the point of epidemics and starvation. By this time, the cases are so serious that alleviating them takes enormous funds and person power, and ends in the loss of life by the millions. Were the concept of care for self and others at the center of public policy along with the economic development plans of a country or region, it could result in new ways of enacting health-alongside and parallel with the enactment of the more traditional markers of development success seen in construction sites. Sustainable development needs to address health for all people, or only the wealthy will enjoy development benefits. The following discussion on solicitude moves the idea of care from an individual to a public sphere.

The common meaning of solicitude reflects a state of concern and anxiousness, more than just care it has the added dimension of attentiveness along with a sense of protection. In the academic arena of Critical Hermeneutics, Paul Ricoeur used solicitude along with self-esteem to posit a way for people to privilege an ethics that is grounded in actions aiming for "a good life with and for others in just institution" [10]. For this ethics to take hold, our individual and collective lives require that we see oneself as another. "Fundamentally equivalent," Ricoeur posits, "are the esteem of the other as oneself and the esteem of oneself as the other" [10]. With this attitude toward others, and ourselves, the capacity for a deep sense of solicitude makes us more alert and even more vulnerable to the suffering of other people. Here suffering moves beyond the physical or psychological and includes a person's capacity for acting. With the destruction of the capacity to act (through unjust policies and institutions or lack of ability to sustain a normal life), comes a "violation of self-integrity" [10]. For a person to fully understand what it must be like for some to suffer the loss of selfintegrity, we must move beyond a sense of sympathy as an exterior value we hold, and onto a value that is part of who we are, our interior that constitutes part of our being. When another's integrity is violated, so is ours. Healing, good health and a good life reflect interdependence with others in the family, the community and the society.

How do we tie together self-esteem, others, and living a good life within an ethical framework? One way could be through health policies designed from the point of view that there will always 
be a plurality of individuals and needs in community and how best do care programs work in such situations where care of the other is a significant factor? The question is asked so that on-theground information can be drawn for a policy framework rather than assuming what will work. Policy needs to stem from lived experiences of policy recipients. A social space needs to be created in which real people with real health issues can be the examples of what kind of care is needed. In addition to the creation of a social space, there also needs to be a centralized role of sustainable development seen through the lens of solicitude for the political sphere. Herein, the theory of solicitude, which holds both the individual and universal aspects of a society, constitutes both theory and practice in healthcare.

For such as Ricoeur's concept of solicitude to take hold in formulating public policy, it would seem that a culture like Cambodia, based in a sense of community and strong familial ties, instead of the deep seated concept of individualism and individual rights, could be more likely to succeed than those holding western ideals of the good life. However, as important as is the cultural context, the primary move would need to be on the part of the Cambodian government to create a public space and political sphere wherein the citizenry affected, in this case those with diabetes, could be engaged sufficiently to have their own voices heard and respected. Moreover, essential to creating this context would be an awareness of the importance of health as reflected in policies stemming from other government venues including education, economics, business, and social policy. The interdependence of these venues afford institutional and political configurations of a country to have as a national goal help for all their people to live well together. Such a platform allows for national healing on multiple levels and the development of full capacity on the part of its citizenry.

\section{Cambodian Field Project Review in Context}

In order to have a concrete example of needed care, we report on one of our rural day clinics set up and run by volunteer nurses. The care policies cannot be determined theoretically or from abstract concepts determining policy, but need to be based in the here-andnow of people on the ground. Before, however, it is important to provide a brief context. The Index of Economic Freedom ranks Cambodia 101 out of 186 countries indicating that more "...than half of the labor force is engaged in subsistence farming, and Cambodia remains one of Asia's poorest countries" [11]. More specifically, approximately, 78 percent of Cambodians live in rural communities [12]. Of the approximately 14 million people living in Cambodia 2400 are killed each year mostly from motorcycle accidents [13]. In the capitol, Phnom Penh, most motorcycle drivers wear helmets, however, adults and children riding behind the driver usually do not. In the rest of Cambodia, helmet wear is inconsistent. Due to the outstanding HIV/AIDS programs supported by the Royal Government of Cambodia and its partners there has been a significant decline in the HIV positive population. In 2010, Cambodia received a prestigious award at the Millennium Development Goal summit. Cambodia's 2010 prevalence rate was about 0.7 compared with a high of about 2 percent in 1997. Over
90 percent of advanced HIV infected adults are on antiretroviral therapy up from 38 per cent in 2006 [14].

The story of type 2 diabetes is very different and alarming. Diabetes is on the increase and has been called the Silent Killer. A person can have diabetes for a long time before symptoms are recognized. Even under these conditions, the disease has increased significantly and people by the hundreds of thousands find themselves living with diabetes. Dr. Lim Keuky, an endocrinologist and head of the Cambodia Diabetes Association, explains the prevalence of type 2 diabetes in the following way: "You can go to every village with me and see it. When I go abroad to developed countries, people say I'm lying. I'm not lying" [4]. Dr. Keuky reports that clinics are crowded with diabetes patients in their late 30's. This is an early age for diabetes to set in. However, in addition to being unaware they have diabetes, Cambodians do not go to a clinic for many reasons including a lack of money, time, travel distance, and interest. Rural people need to be educated about this disease and the dangers of concomitant implications, most particularly heart disease. If Cambodia can upset the earlier HIV/AIDS trend with such amazing results, then with the right mindset, they can set out to respond to the diabetes epidemic. HIV/AIDS entered into the social space in Cambodia; everyone knew about this problem. Moreover, it became part of the political sphere as the government worked with partners both throughout Cambodia and from different parts of the world to respond successfully to this crisis.

The authors have led professional health groups to various countries in Southeast Asia for several years. In Herda and Dzubur [15], a report on clinics in Myanmar describes our work with malaria. We have set up day clinics in Cambodia and have run each one with American nurse and health professional volunteers. Volunteers from other professions, as well as from the local village, also join us since there are myriad tasks to be done in running a day clinic and a learning center. It is an amazing site for the villagers to see their village being important enough for a busload of people to come to help them. These visits provide more than one-time medical help. Perhaps as important as the medical help is the aftermath of our visits. Upon our departure, the villagers begin talking among themselves about diabetes, why some people are sick and die, what they can do about it, how can they work with the government and other topics new to them. The local and provincial government officials ask us to return, however, there are many villages and we feel that the work is as much a wake-up event as it is a medical venture. Our overall purpose is many-fold, with a primary purpose being to bring awareness about diabetes to the rural populations.

Before we go into a country to set up a clinic, we visit the country several times first in order to make friends with the villagers and to know the local and provincial officials. Also, before we bring a group of nurses and nursing students, as well as others who want to help, we apply for and receive permission from all authorities to set up the clinic, as well as a learning center for children. We take a history of each patient, take the person's blood sugar count, record the information, distribute vitamins, first aid supplies, and reading 
glasses if needed, and provide computers for the Cambodian medical and educational personnel. We also bring hundreds of pounds of clothing for villagers. Each person who comes to the clinic receives a meal and a bottle of water. This experience is a first for the vast majority of our patients.

Those with diabetes or with a suspect blood sugar count are informed about medications and diet. To change from white rice to brown rice is important in light of the high glycemic index of Cambodian white rice. It is very difficult to change people's eating habits. Education is key to this change. However, the change that needs to take place will not happen unless an all-embracing understanding of why the change is needed. Simply telling a person what to eat and not to eat usually does not suffice. Unless the self-esteem of the patient is put to risk, there will be little reason to change. Meaningful life for a person entails well-being in physical, mental and social modalities. Unless people see that their old ways of eating is no longer able to support their own capacity for actions, why would they change? Specifically, to change any of one's many traditions, no matter which culture is addressed, the change must relate to the learner in a personal and social way [16]. Otherwise the new actions, in this case, food choices, will seldom take hold. When such changes take place among more than one person in the village, there is opportunity for a communal food consumption pattern to take place. However, to have such changes take place in Cambodia involves a confrontation with the Pride of Cambodia.

Both rice type and quantities consumed matter significantly to changes in risk factors associated with diabetes. A study posted on the US National Library of Medicine of the National Institute of Health on the type and quantity of rice consumed by Cambodians showed how the incidence of diabetes could be reduced. Specifically, with a change in rice with a lower glycemic index along with a reduction in quantity, the projected incidence of type 2 diabetes over a 10 -year period would be reduced by 27 percent due to the rice type change and by 26 percent due to a 25 percent reduction in quantity from current consumption levels [17]. At the Rice Traders World Rice Conference held in Hong Kong in 2013, the Cambodian rice variety, Phka Rumdul, was chosen as the World's Best Rice; this same variety of Cambodian rice was also awarded this designation in 2012. This type of rice is the Pride of Cambodia and was developed through support from Cambodia, Australia and the International Rice Research Institute (IRRI) and was released in 1999 by the Cambodian Agricultural Research and Development Institute [18]. Phka Rumduol rice has a long slender grain and is a fragrant jasmine type. People in Cambodia find this rice to be delicious tasting. The IR66 variety is lower on the glycemic index so the release of the sugar in the body is much slower. However, the taste to many people is not as sweet and tender at the Phka Rumduol, which is higher on the glycemic index. The two varieties of rice used in Sars and Marks study were Phka Rumduol and IR66. This information would be an important aspect in educating people about the value of consuming rice with a lower score on the glycemic index. However, technical information may be less important to know than if people understand that their capacity for action is diminished when they are suffering from diabetes and related illnesses such as heart diseases.

In our visits to villages prior to setting up a clinic, we talk to a variety of people from young to old. Many do not know about diabetes except that those who have it must take medicine. There is virtually no comprehension of the role certain carbohydrates or sugars play in the health of people. They only know what they think tastes good. An example comes from one of the local authorities who told us he knew his blood count was 500, but he didn't care because he liked white noodles and desserts. Unfortunately, and not unexpectedly, shortly after our visit he died.

If the villagers are sick, they know they need money to buy medicine and those who have no money for medicine have no access to any help unless it is from outsiders. For HIV, the government freely supplies medicine for patients. In the case of diabetes, it is not only medicine (if the disease is far enough along) but also a change in food consumption and lifestyle that is required. For a national program to begin and be implemented, the government's responsibility is not only in the arena of health, but also in education, policy, and politics. The questions of how to expand the conversation about health and increase the interest of the government to listen to all voices, especially those from rural communities, must begin with awareness of the dangers of diabetes and the epigenetic factor. This country cannot afford to ignore the current signs of national distress enhanced by its historical tragedy. The economic improvements in Phnom Penh are bright, shinny and impressive; the rich are becoming richer and while the poor have a modicum of increased income, their choice of what kind of food to buy reflects a lack of knowledge about health and well-being.

There is an opening now in Cambodia for a new social space to come into existence, one that acknowledges the longer the Cambodians wait to take charge of their health, the more elusive the cure. The potential is ripe for a new political sphere to emerge embracing many sectors of society including leaders from economic, education, justice, and political sectors on both the rural and city levels. There needs to be a new conversation about diabetes in Cambodia. Not enough people are involved in the one that simply allows those with money to buy medicine at the pharmacies or leave the country for better healthcare.

\section{Challenges and Recommendations}

In 2006 the United Nations designated November 14 as World Diabetes Day and passed Resolution 66/255 in recognition of the need for world leaders to unite in the battle against diabetes [19]. Diabetes ranks sixth as a cause of death in the world [20]. In 2016, six percent of the Cambodian population had diabetes. The prevalence of overweight and obesity among Cambodians is 25 percent. And, ten percent of the population is physically inactive. Blood glucose measurements are not available in primary care facilities [21]. With these statistics it is clear there is an urgency to begin a serious national front against diabetes and related risk factors. 
There are several factors that challenge stemming the tide in the diabetes epidemic in Cambodia:

- Cambodia is rapidly becoming an integral part of the economic rise among Asian nations with aid from China's Belt and Road initiative. The focus is on business partnerships, not health.

- The wealthy people in Cambodia (a small percentage) who have health issues leave the country for healthcare in Singapore or Thailand, or other destinations. They do not need to raise their voice in a cry for health services.

- The people who have no choice but to stay in Cambodia need to pay in cash before they receive treatment. So the health institutions never need to worry about collecting a debt for services. The families who sell everything they own in order to pay for medical services end up in even deeper poverty.

- The Pride of Cambodia, Phka Rumduol rice, was developed with the help of Australia and the Rice International Institute of Research. It is unfortunate that such researchers could not focus on good tasting rice that falls lower on the glycemic index. To take away the Pride of Cambodia is a major cultural undertaking that would meet with little understanding at this time.

- The government is unlikely to increase tax on income to support a universal health care program because then the poor would become even poorer.

One might say, the above challenges could inhibit any action on the part of the government or citizenry to begin combatting the increasing rate of type 2 diabetes in Cambodia. On the other hand, with a combination of understanding the nature of the problem and working with world funding partners, the government could initiate a major battle against this disease by building a social and political infrastructure based on resources within Cambodia. The following recommendations would undergird such an initiative:

- Primary to any initiative, on the part of the government, is the development of a philosophical stance toward the problem along with the choice of a national narrative that embraces alternative actions. An alternative to the traditional lament of not having funds is to look at the capacity of action on the part of all persons. Were Cambodians to think of themselves as part of all others, and that if one segment of society is ill, so are the other segments, a sense of solicitude could be developed.

- Build in-country capacity to collect data from those who are suffering from diabetes along with the family members. These data would be much closer to the realities than if out-ofcountry people came in to collect and analyze the data. Today, in Cambodia, there are enough university trained scientists and analysts to guide such research. Building in-house research abilities is key to providing the right on-the-ground information for the policy makers. Such activities help the local population to take ownership of the problem in concert with the government.

- Designate international partners to fund the program following guidelines that are understood and approved by the Cambodian government.

- Engage local authorities in each province and township to contribute and be held responsible for accuracy.
- Use as an example, the successful war against HIV/AIDS, teaching both government officials and the citizenry that such a goal to reduce and control the incidence of diabetes is entirely within their grasp.

- Set up educational programs for k-12 curriculum as well as adult learning centers to bring both awareness and understanding of the issue at hand. Include in the educational curriculum that the idea of each person's capacity to act and maintain self-integrity is central to one's overall well-being.

The above recommendations, if implemented, could bring into existence not only a working philosophy of solicitude but also a social and political infrastructure that would be ready to absorb outside funding in practical and useful ways. There are too many examples of outside funding being wasted or funding programs that the local people are not even aware. For example, The Gates Foundation and the Merck Foundation gave $\$ 50$ million to address the anti-AIDS program in Botswana, but only 70 percent was spent because of a lack of culturally and technically competent people to distribute and use the funds in appropriate ways [22]. On the other hand, Cambodia has improved all levels of education significantly in the last decade.

Cambodia stepped up to the plate in the war against HIV/AIDS; they can do another campaign, this time against an opponent that is not only developed in the current generation, but one that unless seriously attacked, will be developed in many generations to come. It will take more than outside funding agencies and government support to develop and succeed in such a campaign; it will take the country as a whole. Cambodia is graduating many nurses, teachers, medical doctors and researchers in several fields including social sciences, technological sciences and natural sciences. To use its own resources with outside funding partners, Cambodia can create a fully developed social and political front against the scourge of diabetes, which, in turn, will significantly help Cambodia to prepare for and positively address future health and other types of challenges. Moreover, such an approach develops an interrelated infrastructure within Cambodia that can influence other development fronts, such as security, finance, education, etc. Tapping the local citizenry affords a kind of resource that money cannot buy. This resource resides in the nature of all of us. As Alberto Andretta writes: "[h]umans are the only beings capable of distancing themselves form their experiences and thus capable of raising questions about their being in the world" [23]. More specifically, people can raise questions about universal healthcare in Cambodia, which, in turn, most assuredly relates to one's being. Questions open up possibilities and with possibilities come the potential for on-the-ground actions in concert with government policies. A move toward universal health places solicitude at the center of the political sphere.

There are now many organizations addressing this Silent Killer sponsored by governments, and world organizations such as the United Nations and the World Health Organization, as well as developed nations and private organizations. Economic progress in countries like Cambodia will only be prudent and long lasting 
when the citizens have an opportunity and are allowed to act in the emerging social spaces and political spheres that place care for self and others at the center of efforts toward sustainable development. As Cambodia lives out the determination to curb and control diabetes, it will be an example and a model, not only to other developing worlds, but to the so-called developed worlds as well.

\section{References}

1. Kiernan B. The Pol Pot regime: Race, power, and genocide under the Khmer Rouge, 1975-79. Yale University Press. Edition 3. 2008.

2. Boraden N. The Khmer Rouge: Ideology, militarism, and the revolution that consumed a generation. Praeger Security Series. Praeger. 2013.

3. https://www.sciencedaily.com/releases/2016/12/161212115 737.htm

4. https://www.pri.org/stories/2014-01-29/khmer-rouge-maybe-partly-blame-diabetes-cambodia

5. Snyder M. Genomics and personalized medicine /What everyone needs to know. Oxford University Press. 2016.

6. Cullis P. The personalized medicine revolution/ How diagnosing and treating disease are about the change forever. Greystone Books Ltd. 2015

7. http://discovermagazine.com/2006/nov/cover/article_ view?b_start:int $=3 \&-C$

8. http://www.who.int/hdp/poverty/en

9. https://www.iisd.org/topic/sustainable-development

10. Ricoeur P. Oneself as Another. The University of Chicago Press. Trans Kathleen Blamey. 1992; 174: 190-194.
11. https://www.heritage.org/index/country/cambodia

12. https://opendevelopmentcambodia.net/topics/population-andcensuses

13. http://www.who.int/violence_injury_prevention/road_traffic/ countrywork/khm/en

14. https://www.unicef.org/cambodia/4.HIV.pdf

15. Herda EA, Dzubur VG. The Power of Narrative and Local Tradition in International Health Development: Reducing the Incidence of Malaria Among Three Villages in SE Asia. Asian Economic and Social Society. 2017; 5: 381-291.

16. Herda EA. A leadership and adult learning protocol for a SE Asia health development project: history, culture and imagination in action. Humanity, History and Society, Ming Zhang (Editor). Singapore: IACSIT Press. 2012; 42: 43-46.

17. Sar S, Marks GS. Estimated effects of white rice consumption and rice variety selection on incidence of type 2 diabetes in Cambodia. Public Health Nutr. 2015; 18: 2592-2599.

18. http://news.irri.org/2014/01/cambodia-rice-variety-namedworlds-best.html

19. Silink M. A United Nations Resolution on Diabetes The Result of a Joint Effort in US Endocrinology. 2007; 1: 12-14.

20. http://www.who.int/gho/mortality_burden_disease/causes death/top_10/en

21. http://www.who.int/diabetes/country-profiles/khm_en.pdf)

22. http://issues.org/21-1/p_csaszar

23. Andretta A. An interpretive analysis of work: inquiry into sustainable development in Tanzania and Jilin, China. Doctoral Dissertation, University of San Francisco. 2005; 173.

(C) 2018 Ellen A. Herda \& Valerie G. Dzubur. This article is distributed under the terms of the Creative Commons Attribution 4.0 International License 